\title{
ASSOCIATION OF TESTOSTERONE AND CHOLESTEROL LEVEL IN MODULATION OF IMMUNITY AND SEVERITY OF DISEASE IN VISCERAL LEISHMANIASIS PATIENTS-A PRELIMINARY STUDY
}

\author{
${ }^{1}$ Krishna Pandey, ${ }^{2}$ Dharmendra Singh, ${ }^{3}$ Sanjiva Bimal, ${ }^{4}$ Krishna Murti and ${ }^{2}$ Pradeep Das \\ ${ }^{1,2,3}$ Rajendra Memorial Research Institute of Medical Sciences, \\ Indian Council of Medical Research, Agamkuan, Patna-800007, Bihar, India \\ ${ }^{4}$ National Institute of Pharmaceutical Education and Research, Hajipur-844102, Bihar, India
}

Received 2014-02-28; Revised 2014-03-13; Accepted 2014-03-25

\begin{abstract}
Males are more prone to Visceral Leishmaniasis (VL) as compared to females. The role of androgens in host defence against Leishmania and other pathogens is of considerable interest. This study was aimed to understand a baseline mechanistic understanding of the pathogenesis of visceral leishmaniasis with respect to testosterone. We examined the relationship between serum testosterone and cholesterol levels, antigen induced Interleukin-10 (IL-10) and Interferon-gamma (IFN- $\gamma$ ) and production by Peripheral Blood Mono Nuclear Cells (PBMCs) and parasite burden as determined by microscopic examination on male patients (n $=18)$ with VL and gender-and age-matched controls $(n=10)$. Testosterone plasma levels were found to be up regulated in VL patients as compared to healthy controls. In severely infected patients, the mean testosterone concentration was observed to be increased compared with other VL patients $(p<0.001)$. Further, serum cholesterol level was found much down regulated during severe infection of $\mathrm{VL}(\mathrm{p}<0.005)$ as compared to healthy control. Further an in-vitro stimulation of PBMCs of VL patients with exogenous testosterone resulted in an increase IL-10 production with a subsequent decline in host protective IFN- $\gamma$ response. This study suggests that testosterone level might be linked to immuno-pathogenicity of VL infection. Whether testosterone level is probably a marker of severe VL infection with an immunosuppressive effect needs to be validated further.
\end{abstract}

Keywords: Visceral Leishmaniasis, Testosterone, Interleukin-10, Hypocholestrolemia

\section{INTRODUCTION}

Visceral Leishmaniasis (VL), also known as kalaazar, is a protozoan disease typically caused by Leishmania donovani complex, which includes three species L. donovani (Indian subcontinent and East Africa), L. infantum (Mediterranean basin) and $L$. chagasi (Latin America). It is transmitted to humans by bites of female infected sand flies (vector) Phlebotomus (old world) and Lutzomia (New world). This disease is endemic in 62 countries; $90 \%$ of the estimated 200,000-
400,000 new cases and more than 20,000-40,000 deaths occur in rural areas of India, Nepal, Bangladesh, Sudan and Brazil; as many as one half of the cases of VL occur in India (Desjeux, 1992; 1996; 2004; Alvar et al., 2012). The disease affects mainly the poor rural and causes fever, hepatosplenomegaly, pancytopenia and wasting. Barriers impeding the effective control of VL, in India and elsewhere are the limited availability of proper medical facilities, incomplete course of treatment and limited treatment options. For many years, Sodium Antimony Gluconate (SAG) has been used as the first $\begin{aligned} \text { Corresponding Author: } & \text { Krishna Pandey and Dharmendra Singh, Rajendra Memorial Research Institute of Medical Sciences, } \\ & \text { (Indian Council of Medical Research), Agamkuan, Patna-800007, Bihar, India, Tel: +91 612 2631565; } \\ & \text { Mob: +91 7677435674; Fax: +91 } 6122634379\end{aligned}$ 
line treatment in many countries including India. Recently, increasing rates of resistance of L. donovani to SAG in India have led to the consideration of alternative drugs such as oral miltefosine and parenteral amphotericin-B as first line treatment (Sundar et al., 1997; Das et al., 2005; Abdo et al., 2003; Sundar et al., 2006; Thakur and Narayan, 2004). As known, VL patients require an interferon- $\gamma(\mathrm{IFN}-\gamma)$ T-helper cell type 1 (Th1) response to initiate lytic mechanism within macrophages which leads to immune containment of the parasite load (Thakur et al., 2003; Bimal et al., 2008). However, the Th1 kind of response remains suppressed in patients and it has been shown that this suppression was regulated by IL-10 (Carvalho et al., 1994). In active VL patients of Sudan and India, production of high levels of IL-10 mRNA was reported suggesting conclusive role of IL-10 for progressive immunopathology in patients (Karp et al., 1993; Ghalib et al., 1993; Kenney et al., 1998).

Notably, several epidemiological analyses reflect that most often, males are at greater risk of developing clinical leishmaniasis such as Cutaneous Leishmaniasis (CL), Mucocutaneous Leishmaniasis (ML) and VL (Snider et al., 2009). Studies of VL in humans have also exhibited a similar trend for L.chagasi infections in Brazil and L.donovani infections in Somalia (Jeronimo et al., 2004; Shiddo et al., 1995). The underlying mechanism of such gender biased occurrence of clinical leishmaniasis remains by and large unclear. One murine study however has demonstrated that female DBA/2 mice secreted more IFN- $\gamma$ compared to male against L.mexicana infection. On the other hand, male mice exhibited high level of Th2 associated IgG antibodies, which was not detectable in female mice (Satoskar et al., 1998). Some contradictory reports are also available which either indicate that gender may not be a factor in acquiring L. panamensis or even that in certain regions, females could be more susceptible to L. tropica (Munoz and Davies, 2006; Reithinger et al., 2003). Studies regarding role of testosterone in mucocutaneous leishmaniasis is also reported but there is paucity of literature regarding role of testosterone and cholesterol in VL in India and this study will contribute to scientific literature.

In human body, one of the major sites of Leishmania infection is liver, where the cholesterol is synthesized. In human disease severity was also found to be associated with a decreased cholesterol profile in paediatric VL patients. Total serum cholesterol determination can provide understanding of parasite burden in patients with visceral leishmaniasis infection (Lal et al., 2010). Since, cholesterol is playing its important role in the disease severity and cholesterol is the precursor molecule for the production of testosterone. Hence, the study of testosterone and cholesterol is required to be explored.

To what extent immune intervention might influence the occurrence of clinical situation preferably in male population is less understood. In one study, the resistance of female subjects of acquiring cutaneous leishmaniasis correlated with higher level of GM-CSF, a growth factor known to facilitate differentiation of macrophage and dendritic cells. Successful treatment of refractory CL with GMCSF and antimonials has also been reported in a study (Lezama-Davila et al., 2007; Almeida et al., 2005).

While these factors probably play a role in the gender differences seen in clinical cases of leishmaniasis. Several studies signify that modulation of infection by sex hormones can be also outcome of the disease. Evidence has indicated that both testosterone, the major circulating androgen in male and progesterone, a hormone linked to maintenance of pregnancy are immuno-suppressive. These hormones impair macrophage production of TNF- $\alpha$ and NO, suppress NF$\mathrm{kB}$ signal transduction which is a pre-requisite for proinflammatory cytokine production and promotes IL-10 production and STAT-6 transduction known to upregulate IL-4 (Piccinni et al., 1995; Miller and Hunt, 1998; D'Agostino et al., 1999). Although, one study confirmed that treatment with exogenous testosterone enhanced disease exacerbation of VL in hamsters, our understanding on sex-hormones in human VL patients in relation to disease exacerbation is poor and needs to be investigated (Yin et al., 1998).

In human disease severity was also found to be associated with a decreased cholesterol profile in paediatric VL patients. Cholesterol is largely reported about its role in the parasitic infection. It nicely exerts its effect through its membrane domain termed lipid raft through which it facilitates signal transduction to allow pathogen gain entry into the host cells (Simons and Toomre, 2000; Lal et al., 2007; Ghosh et al., 2011). Whether or not an association exists between sexhormones and cholesterol in relation to disease exacerbation is also not properly understood.

In this study, we examined the influence of severity of VL infection on the testosterone and cholesterol level as well as the possible effect of hormonal imbalances on pathogenicity of VL on the basis of IL-10 production by these patients. IL-10 suppresses the activity of IFN- $\gamma$ which is the host protection based cytokine. 


\section{MATERIALS AND METHODS}

\subsection{Study Population}

The present study was approved by the Institutional Ethical Committee (IEC) and a written informed consent was obtained from all human subjects. The clinically suspected VL subjects hailing from various endemic districts of Bihar, without history of treatment for VL and aged between 15 to 50 years, were recruited at the out-patient-clinic of Rajendra Memorial Research Institute of Medical Sciences between March 2010 and February 2011. The clinical VL suspects were subjected to serological test (rK39 strip test), splenic aspirate examination for L.D. (Leishmania donovani) body and blood PCR. As the sensitivity of bone marrow smear is low, splenic smear examination were considered for confirmation of parasitological diagnosis. After baseline diagnostic workup patient with suspected VL underwent splenic aspiration and smear examination. Ten age-sex matched endemic individuals without any clinical signs and symptoms of VL were included as healthy controls. Blood was collected for estimation of testosterone, immunological test and biochemical analysis. For testosterone estimation, serum $\left(1.5 \mathrm{~mL}^{-1}\right)$ was collected from patients and controls in $1.8 \mathrm{~mL}$ cryogenic vial (Corning®). For immunological and biochemical investigations, heparinised samples of venous blood were also collected from patients and controls. Based on Parasitic Load (PL), patients were divided into three groups; group A with PL of grade $1+(n=6)$, group B with PL of grade $2-3+(n=6)$ and group C with PL>3+ $(n=6)$. The endemic healthy controls were negative by rK-39 serological test (blood, serum, urine and sputum) and blood PCR.

\subsection{Inclusion and Exclusion Criteria}

The patients who gave informed consent were consecutively enrolled in the study until completion of prior determined sample size. All the patients belonged to male sex and were between the age group of 15 to 50 years. All clinical suspects presenting to the out-patientclinic of RMRIMS with a history of fever of 2 weeks duration or more and with splenomegaly were considered as eligible for the study. Parasitological examinations were performed on these clinically suspected male VL patients. After confirming the presence of LD bodies in the splenic aspirate, the patients were included, admitted in the ward and were given treatment as per the standard drug regimen (Amphotericin B, $1 \mathrm{mg} / \mathrm{kg} /$ body weight in $5 \%$ dextrose on alternate days for 15 injections). Patients below the age of 15 years, with past kala-azar history, positive HIV, HbsAg and HCV serology test, abnormal renal function tests (Serum creatinine and blood urea nitrogen), abnormal liver function tests (Serum bilirubin, Alanine transaminase and Aspartate transaminase) and those who refused to give consent for the study were excluded.

\subsection{Investigations}

All the study subjects were examined clinically and admitted in the indoor ward of RMRIMS, Patna. Body weight, temperature, liver and spleen size were measured. Blood, sputum and urine samples were collected from all the study subjects including control. On-the-spot serological test was performed using rK-39 strip (In Bios International, Seattle, WA) and the remaining blood samples were transported for further laboratory investigations including minicircle of kinetoplast-DNA (kDNA) blood PCR for VL (Sundar et al., 1998; Singh et al., 2009; 2013; Salotra et al., 2001). Routine Clinical biochemical assays, such as serum bilirubin, serum aspartate and alanine transminase, serum cholesterol, blood urea nitrogen and creatinine levels were performed on serum samples, obtained from the patients and controls. Estimation of total serum cholesterol was done using overnight fasting samples of patients and controls. None of the patients were using statins (HMG-CoA reductase inhibitors). Pathological investigations included total and differential white blood cell counts, total protein and haemoglobulin (Hb levels). In addition, serological tests for the human immunodeficiency virus, hepatitis $\mathrm{B}$ and $\mathrm{C}$ were performed in each case. The clinically and serologically suspected individuals were subjected to microscopic examination of Giemsa stained smear of splenic aspirates for parasitological confirmation of the disease. The following standard grading system for parasite load was used: 1-10 amastigotes/1000 oil immersion fields (1+), 1-10 amastigotes/100 oil immersion fields (2+), 1-10 amastigotes/10 oil immersion fields (3+), 1-10 amastigotes/1 oil immersion fields (4+) and 10-100 amastigotes/1 oil immersion fields (5+) (Chulay and Bryceson, 1983).

\subsection{Testosterone Assays}

Direct Immunoenzymatic Assay (DIA) was applied for the quantitative determination of testosterone in serum. Briefly, $25 \mu \mathrm{L}$ serum samples from patients and controls were added to anti-testosterone IgG antibody coated wells in a 96 well micro titre plate $12 \times 8$-wells (Equipar, Italy). Standard calibration samples of 0, 0.2, 
1.0, 4.0 and $16 \mathrm{ng} \mathrm{mL} \mathrm{m}^{-1}$ were also added in separate wells. This followed subsequent incubation of samples with $100 \mu \mathrm{L}^{-1}$ proteic buffer solution containing testosterone conjugated with Horseradish Peroxidise (HRP), provided with the kit, for $60 \mathrm{~min}$ at $37^{\circ} \mathrm{C}$ that allowed binding of testosterone present in sample to the immobilized antibodies. After washing, $100 \mu \mathrm{L}^{-1}$ of enzyme substrate containing Tetramethylbenzedine (TMB) diluted in phosphate/citrate buffer was added and incubated for $15 \mathrm{~min}$ at room temperature in the dark. The reaction was terminated by adding stopping solution of $0.3 \mathrm{M}$ sulphuric acid. Absorbance of each well against blanking well was measured at $450 \mathrm{~nm}$ in a plate reader within $30 \mathrm{~min}$. The colour intensity was inversely proportional to the testosterone concentration in the sample.

\subsection{Effect of Testosterone on Release of Cytokine IL-10 Level}

Heparinized venous blood from VL patients and control was diluted in 1 in 5 with endotoxin free RPMI1640 (Gibco) supplemented with penicillin, streptomycin and glutamine $(2 \mathrm{~mm})$ and cultured in 24 well plates (NUNC). The cells were stimulated with $0.4 \mu \mathrm{m}$ of water soluble testosterone which was dissolved in ethanol. Simultaneous stimulations were performed with $10 \mu \mathrm{g}$ $\mathrm{mL}^{-1}$ of Soluble Leishmania Antigen (SLA) and PMAionomycin in independent wells and the supernatants were harvested after $24 \mathrm{~h}$ and stored at $-80^{\circ} \mathrm{C}$. Earlier, the Soluble Leishmania Antigen (SLA) was prepared from $1 \times 10^{7} / \mathrm{mL}^{-1}$ stationary phase Leishmania donovani promastigotes suspended in phosphate buffered saline ( $\mathrm{pH}$ 7.4). The suspension was vortex five times for $2 \mathrm{~min}$ each with a $10 \mathrm{~min}$ interval and stored in liquid nitrogen. The pellets thus obtained were re-suspended in $10 \mathrm{~mL}$ of the PBS and sonicate at $4^{\circ} \mathrm{C}$ five times for $1 \mathrm{~min}$ in an ultrasonicator ( $80 \%$ amplitude, $0.5 \mathrm{~min}$ pulse). The suspension was finally centrifuged at $6000 \times \mathrm{g}$ for $20 \mathrm{~min}$ at $4^{\circ} \mathrm{C}$. The supernatant containing the soluble leishmania antigen was collected and stored at $-70^{\circ} \mathrm{C}$. The amount of SLA was adjusted at $10 \mu \mathrm{g} 5 \mu \mathrm{L}^{-1}$. Cytokine were measured with specific immuno assay according to manufacturer's instructions. The detection limits were $7.8 \mathrm{pg} \mathrm{mL}^{-1}$ for IFN- $\gamma$ (BD, USA), $2 \mathrm{pg} \mathrm{mL}^{-1}$ for IL-10 (BD, USA) and $4 \mathrm{pg} \mathrm{mL}^{-1}$.

\subsection{Treatment}

The patients who were confirmed clinically, serologically and parasitologically for VL were admitted in the indoor ward of the institute and were treated with intravenous Amphotericin B 1mg/kg/body weight in 5\% dextrose for 15 injections alternate day. They were clinically and parasitologically cured after treatment. These were followed-up to one year. None of them had relapse of VL or progression to Post Kala-azar Dermal Leishmanisis (PKDL).

\subsection{Statistical Analysis}

The testosterone and IL-10 levels of patients were compared with controls using Mann Whitney test and comparison between different levels of infectivity in VL patients with control was done using the KruskalWallis nonparametric test using SPSS software (SPSS, Version 16).

\section{RESULTS}

The results are presented as a correlation of routine laboratory and anthropometric measurements with parasite burden, testosterone and cholesterol levels (Table 1). The clinical variables for total count and differential count in the different groups of VL patients were comparable. Based on severity of VL as determined by parasite burden, in group C (Severe VL patients) had low Body Mass Index (BMI) compared to group A (low infection group, $\mathrm{p}<0.001$ ) and group $\mathrm{B}$ (moderate infection group, $\mathrm{p}<0.05)$. In comparison, the patients with moderate to low infection showed a better BMI ( $p>0.05)$. On the other hand, it appeared that severity of VL had little impact on creatinine and transmission level compared to control $(p>0.005)$. Significantly lower cholesterol levels were observed in all categories of VL patients than the healthy control $(\mathrm{p}<0.005)$. Group $\mathrm{C}$ (severe VL patients) had low cholesterol compared to group A (low infection group, $\mathrm{p}<0.001$ ) and group B (moderate infection group, $\mathrm{p}<0.05$ ). Subsequent data revealed that testosterone level was increased in VL cases compared to healthy controls $(\mathrm{p}<0.05)$. In severe VL patients (group C) higher testosterone levels were observed compared to group A (low VL infection, $\mathrm{p}<0.001$ ) and group B (moderate VL infection, $\mathrm{p}<0.05$ ).

The serum transaminase, blood urea, creatinine were observed to be within normal reference range while the serum cholesterol was found much down regulated in group C (Range 38.0-50.9 $\mathrm{mg} \mathrm{dL^{-1 }}$ ). The serum cholesterol was between 58.2 to $71.0 \mathrm{mg} \mathrm{dL}^{-1}$ and 84.5 to $101.6 \mathrm{mg} \mathrm{dL}^{-1}$ in group $\mathrm{B}$ and $\mathrm{A}$ respectively. In severe VL infection (group C), serum testosterone level was also observed to be up regulated. It appears that high serum testosterone in higher parasitic load group may be due to down regulated serum cholesterol, since cholesterol is a prerequisite precursor of testosterone in the human body. 
Table 1. Biochemical investigations, duration of illness and testosterone levels in VL patients compared to control

\begin{tabular}{|c|c|c|c|c|}
\hline \multirow[b]{2}{*}{ Parameters } & \multicolumn{4}{|l|}{ Groups } \\
\hline & $\begin{array}{l}\text { Low } \\
\text { (group A) }\end{array}$ & $\begin{array}{l}\text { Moderate } \\
\text { (group B) }\end{array}$ & $\begin{array}{l}\text { Severe } \\
\text { (group-C) }\end{array}$ & $\begin{array}{l}\text { Healthy } \\
\text { controls }\end{array}$ \\
\hline Mean age (years) & $18 \pm 11.4$ & $19.4 \pm 5.7$ & $28 \pm 8.55$ & $24.75 \pm 8.7$ \\
\hline Parasitic load & 1+ L.D. bodies & 2-3+ L.D. bodies & >3 L.D. bodies & NA \\
\hline Duration of illness (days) & $22.85 \pm 7.2$ & $25.60 \pm 15.00$ & $30.10 \pm 15.00$ & NA \\
\hline Total white blood cells $(\mathrm{cmm})$ & $3639 \pm 216$ & $4864 \pm 245$ & $3457 \pm 130$ & $4194 \pm 415$ \\
\hline Neutrophils (\%) & $44.80 \pm 13.30$ & $43.09 \pm 13.25$ & $40.16 \pm 13.7$ & $3.3 \pm 1.7$ \\
\hline Lymphocyte (\%) & $49.82 \pm 1.39$ & $44.53 \pm 1.43$ & $52.51 \pm 1.41$ & $23.4 \pm 2.6$ \\
\hline Eosinophil (\%) & $2.52 \pm 6.66$ & $6.21 \pm 2.36$ & $2.42 \pm 2.95$ & $2.0 \pm 0.3$ \\
\hline Body mass index $\left(\mathrm{Kg} / \mathrm{m}^{2}\right)$ & $\begin{array}{l}20.5 \pm 5.6 \\
* \mathrm{BMI}, \mathrm{p}<0.005\end{array}$ & $15.5 \pm 2.3$ & $10.33 \pm 5.1$ & $24.00+2.10$ \\
\hline $\operatorname{ALAT}(\mathrm{u} / \mathrm{L})$ & $17.0 \pm 3.5$ & $18.5 \pm 5.5$ & $21.0 \pm 3.25$ & $23.10 \pm 5.60$ \\
\hline Creatinine (mg/dL) & $\begin{array}{l}0.50 \pm 0.12 \\
* \mathrm{P}^{\mathrm{C}}, \mathrm{p}>0.005\end{array}$ & $0.72 \pm 0.12$ & $0.69 \pm 0.15$ & $0.45 \pm 0.15$ \\
\hline Cholesterol (mg/dL) & $94.33 \pm 7.79$ & $66.86 \pm 4.76$ & $\begin{array}{l}43.68 \pm 4.69 \\
* \mathrm{C}(\mathrm{p}<0.005)\end{array}$ & $145.0 \pm 22.5$ \\
\hline Testosterone (ng/mL) & $0.687 \pm 0.05$ & $1.82 \pm 0.36$ & $\begin{array}{l}2.32 \pm 2.23 \\
* \mathrm{~T}=(\mathrm{p}<0.001)\end{array}$ & $0.476 \pm 0.05$ \\
\hline
\end{tabular}

Mean \pm SD $(\mathrm{n}=6)$, ALAT: Alanine amino transferase; IL-10: Interleukin-10., ${ }^{*} \mathrm{~T}=\mathrm{p}<0.001$ : Patients with severe VL demonstrated higher testosterone level compared with patients with low infection (group $\mathrm{A},{ }^{*} \mathrm{C}=\mathrm{p}<0.005$ compared other VL patients (group A and B) and control, ${ }^{*} \mathrm{BMI}, \mathrm{p}<0.005$ : VL patients with low parasite load observed with significantly high BMI index compared to VL patients with severe infection, ${ }^{*} \mathrm{P}^{\mathrm{C}}, \mathrm{p}>0.005$, No significant difference was observed between creatinine level of VL patients based on parasite load

Table 2. Effect of testosterone on levels of IL-10 and IFN- $\gamma$ in human VL patients and healthy control

\begin{tabular}{|c|c|c|c|c|}
\hline \multirow[b]{3}{*}{ Stimulation } & \multicolumn{4}{|c|}{ Cytokines (pg/mL) } \\
\hline & \multicolumn{2}{|l|}{ IL-10 } & \multicolumn{2}{|l|}{ IFN- $\gamma$} \\
\hline & $\mathrm{VL}$ & Healthy & VL & Healthy \\
\hline None & $2.23 \pm 0.5$ & $0.82 \pm 0.01$ & $50 \pm 1.25$ & $134.5 \pm 1.56$ \\
\hline Along with testosterone & $\begin{array}{l}38.17 \pm 1.21 \\
* \mathrm{p}<0.001\end{array}$ & $8.52 \pm 1.51$ & $84.8 \pm 1.28$ & $124.43 \pm 6.78$ \\
\hline Along with SLA & $26.17 \pm 1.19$ & $9.65 \pm 2.74$ & $155 \pm 2.55$ & $121.33 \pm 2.3$ \\
\hline Along with Ionomycin & $24.2 \pm 1.51$ & $12.2 \pm 1.51$ & $280.3 \pm 3.5$ & $178.5 \pm 1.2$ \\
\hline
\end{tabular}

To understand testosterone related impact of cytokine immune response during $\mathrm{VL}$, we investigated the secreted levels of IL-10 and IFN- $\gamma$ that were produced in response to stimulation with SLA, testosterone and PMA-Ionomycin by quantikine-ELISA (Table 2). The levels of IFN- $\gamma$ in response to testosterone in VL patients were lower than those of healthy controls $(p<0.001)$. In healthy controls, the effect of testosterone on IFN- $\gamma$ production was not much different than that of SLA $(p>0.05)$. However, in VL patients the effect of testosterone was significantly lower than that of SLA $(\mathrm{p}<0.001)$. The levels of IL-10 produced in response to testosterone during VL were higher compared with the SLA and PMA-Ionomycin stimulated group. The VL cases released $\sim 38.17 \mathrm{pg} \mathrm{mL}^{-1}$ IL-10 against testosterone stimulation and $\sim 26.17 \mathrm{pg} \mathrm{mL}^{-1}$ IL-10 against the SLA stimulation $(p<0.01)$. In healthy controls, the effect of testosterone on IL-10 production was not much different than that of SLA and PMA-Ionomycin ( $p>0.05)$.

\section{DISCUSSION}

Even though, males tend to be more susceptible to VL than females, no previous study has focussed to analyse the basis of this preferentially biased gender difference exhibited in the immune response of human cases to VL. Testosterone modulation of increased infection in macrophages was reported in animal model of VL (Zhang et al., 2001). Very little is known about whether testosterone has direct influence on Leishmania 
donovani infection in humans (Cutolo et al., 2005). Immunological findings reported in this study showed a direct correlation between the clinical features and level of testosterone of the Kala-azar cases. Thus, a severe case with higher parasite load showed more testosterone in their plasma while minimum testosterone in plasma was evident at lower level of infection in a Kala-azar patient having lesser parasite load. It precisely suggests that testosterone might be involved in the disease progression. Whether testosterone could be found to be expressed predominantly in the lymphoid organs during severe parasite multiplication in a chronic kala-azar case needs to be further investigated. Evidence is accumulating which also suggests that testosterone levels might decrease in multiple pro-inflammatory states, including critical illnesses and metabolic syndrome. The presence of androgen receptor was reported in primary culture of human synovial macrophages (Benten et al., 1999). Previous studies has also documented that male sex hormone, testosterone plays an important role for infections with parasitic protozoans inducing an immuno-suppressive effect (Greenblatt, 1980; Alexander, 1988). Macrophages and lymphocytes, the two major cell types involved in the disease outcome of leishmaniasis, possesses receptors for sex hormones such as androgen, estrogens and progesterone (Wunderlich et al., 2002; Danel et al., 1983; Jones et al., 2008). Based on these data it is not surprising that testosterone could affect the outcomes of VL.

Even, the cholesterol levels were lower in more severe stage of VL. In a recent study, hypocholesterolemia and increased triglyceride in paediatric visceral leishmaniasis has been observed and it has also been found that total serum cholesterol determination can provide an understanding of parasite burden in patients with VL infection (Simons and Toomre, 2000; Lal et al., 2007). Cholesterol is the key molecule in the synthesis of both male and female sex hormones. Thus, we hypothesized that it is probably the common occurrence of inflammation reducing total cholesterol which is likely to increase levels of sex hormones such as testosterone. Levels of other sex hormones were not measured in this study. In general, about $50 \%$ of serum cholesterol is derived from dietary cholesterol and $50 \%$ is generated biosynthetically. The VL may lead to anorexia, hence the origin of the lower cholesterol may reduce dietary intake, not the down regulation of biosynthetic pathway (Ghosh et al., 2011).

Even though, severely infected VL cases had high testosterone level, this study indicated that testosterone which remains a major circulating androgen in male individuals was mainly immuno-suppressive in $\mathrm{VL}$ patients. Results of the cytokine analysis of this study clearly demonstrated that expression of IFN- $\gamma$ in testosterone treated samples of VL patients was reduced than those of healthy control, that there was slight augmentation of this expression in controls in response to testosterone. Overall, IFN- $\gamma$ production in VL patients was markedly reduced compared with control. Testosterone increased IFN- $\gamma$ production from unstimulated control, however this increase in IFN- $\gamma$ was greatly reduced as compared to test control. The levels of IFN- $\gamma$ in response to testosterone in healthy control were decreased marginally from unstimulated control but the difference was not of any statistical significance $(\mathrm{p}>0.05)$. As healthy controls were not exposed to Leishmania infection, there was no question of antigen processing and presentation and subsequent immune activation. As such there was marginal change in level of IFN- $\gamma$ in response to testosterone in unstimulated control than healthy controls. Further the SLA stimulation increased the IFN- $\gamma$ production in VL patients than healthy controls. It is well established that antigen driven CMI response (Th1 response) is poor. However, both Th1 and Th2 cell response is likely to be triggered in Kala-azar (Ghalib et al., 1993). SLA stimulation decreased IFN- $\gamma$ production in healthy control, as in healthy control there was no recall response previously unaffected with parasites. The present study also revealed that the difference in IFN- $\gamma$ production between VL patients and healthy controls were significant in unstimulated conditions for which we observed difference in stimulated condition as well. It is usually believed that IFN- $\gamma$ is the pre-dominant cytokine in antileishmanial defence (Carrera et al., 1996; Taylor and Murray, 1998). It functions through its receptor, IGNGR1 and IFNGR2 which are expressed nearly on all cell surfaces. As macrophage and T-cells both possess testosterone receptor, it is not surprising that increased level of testosterone in VL cases affected IFN- $\gamma$ production and that these events collectively influenced the clinical severity of VL. Although not discussed widely in VL, evidence has indicated that sex hormones can have a major impact in the development of immune response. For instance, as known, the Nuclear FactorKappa B (NF-kB)/REL family of transcription factors has a central role in coordinating the expression of a wide variety of genes that control immune responses and in relation to it reports are available which suggest 
involvement of testosterone in suppression of NF-kB signal transduction ( $\mathrm{Li}$ and Verma, 2002). The reports on testosterone signalling in T-cells and macrophages are already available and it was also shown earlier that this hormone also suppress NF-kB signal transduction (Li and Verma, 2002). Of relevance to infection, NF-kB has been shown to be required for the production of IL12 and IFN- $\gamma$ as well as Inducible Nitrite Oxide Synthase (iNOS) (Zhang et al., 2001; Grigoriadis et al., 1996; Sica et al., 1996; Sanjabi et al., 2000).

After incorporating the results obtained in the present study, it seems possible that observed increase in testosterone with concomitant decrease in IFN- $\gamma$ in presence of exogeneous testosterone may reflect strong control of sex hormones during initiation of activation events in T-cells also during VL.

However, relationship of release of testosterone with IFN- $\gamma$ down regulation may only represent initial steps and cannot explain the profuse defects in the cellular immune response to parasite. Interestingly, IL-10 production levels were directly correlated with testosterone stimulation. If IL-10 secretion acts by promoting immune suppression and exacerbating the disease, based on the data obtained, testosterone stimulation was happening to increase the IL-10 secretion in the VL cases that were at greater risk for severe disease. Sex hormones modulating inflammatory mediators produced by macrophages cannot be ruled out and increased production of Th2-associated antiinflammatory cytokines such as IL-10 was previously observed (D'Agostino et al., 1999). Although IL-10 levels in VL patients have in general, been found to correlate with immune pathology, the effect of testosterone to trigger IL-10 and the abilities of the VL cases to produce IL-10 in general are perhaps related. Together with our results, this information only indicates that testosterone may have implications for immunoregulation of cellular responses. Through IL-10 production, antigen presentation could be inhibited, while a decrease of IFN- $\gamma$ could have further inhibitory effect on TNF- $\alpha$. As previously shown in VL patients, IL-10, IL-4, IL-13 and TGF- $\beta$ are recognized as key cytokines, the up regulation in the production of which lower the IFN- $\gamma$ dominant protective Th1 cell associated mechanism, thereby deactivating $L$. donovani infected macrophages and fostering progressive intracellular infection (Gomes-Pereira et al., 2004; Jones et al., 2000; Murray and Delph-Etienne, 2000).

Earlier studies have also revealed that the male sex hormone, testosterone, plays an important role in sex dependant resistance in Trypanosoma rhodesiense infection in mice inducing an immuno-suppressive effect in many diseases (Greenblatt and Rosenstreich, 1984). Similarly, such relevance has been shown in infection with Strongyloides ratti in C57BL/6 mice (Kiyota et al., 1984). The over expression in the level of these cytokines considerably affects macrophage activating effecter response particularly of interferon- $\gamma$ which is known to switch on various activation cascades within macrophages and facilitates immune containment of the parasite load (Thakur et al., 2003; Bimal et al., 2008).

\section{CONCLUSION}

It is apparent from this study that sex hormone such as testosterone can directly interact with cells of immune system and influences the development of immune response during VL. The mechanism how this testosterone modulation of immune response during $L$. donovani infection is linked to hypocholesterolemia which remains a conspicuous feature of disease might suggest towards a combined network influencing the regulation of disease in human clinical situation particularly VL.

\section{LIMITATIONS}

It was a preliminary study conducted on a small sample size of Indian kala-azar/VL male patients. This was the first study of this kind directly done on the role of androgens in influencing immune response in Indian VL patients. A similar kind of study on a large sample size incorporating both sexes can contribute significantly in confirming the role of sex hormones in immunopathogenesis of VL. A further study is warranted including determination of sex hormones pre and post treatment as well as in patients having co-infections of VL-HIV, VL-Tuberculosis etc.

\subsection{Conflict of Interests}

The authors declare no conflict of interest.

\section{ACKNOWLEDGEMENT}

For this publication, we are extremely thankful to Dr. Vishwa Mohan Katoch, Secretary, DHR and Director General of Indian Council of Medical Research (ICMR), New Delhi, India for the intramural funding and providing continuous guidance and support. The authors wish to thank the sincere technical support rendered by Mr. Naresh Kumar Sinha (Technical Assistant) Mr. 
Manohar Kumar (Technician) and Mr. Santosh Kumar Sinha (Technician) during the work and also in preparation of the manuscript.

\section{REFERENCES}

Abdo, M.G., W.M. Elamin, E.A. Khalil and M.M. Mukhtar, 2003. Antimony-resistant Leishmania donovaniin eastern Sudan: incidence and in vitro correlation. East Mediterr Health J., 9: 837-843. PMID: 15748080

Alexander, J., 1988. Sex differences and cross-immunity in DBA/2 mice infected with L. mexicana and L. major. Parasitology, 96: 297-302. DOI: 10.1017/S0031182000058303

Almeida, R.P., J. Brito, P.L. Machado, A.R. De Jesus and A. Schriefer et al., 2005. Successful treatment of refractory cutaneous leishmaniasis with GM-CSF and antimonials. Am. J. Trop. Med. Hyg., 73: 79-81. PMID: 16014838

Alvar, J., I.D. Vélez, C. Bern, M. Herrero and P. Desjeux et al., 2012. The WHO Leishmaniasis Control Team, Leishmaniasis worldwide and global estimates of its incidence. PLoS One. DOI: 10.1371/journal.pone.0035671

Benten, W.P., M. Lieberherr, G. Giese, C. Wrehlke and O. Stramm et al., 1999. Functional testosterone receptors in plasma membranes of T cells. FASEB J., 13: 123-33. PMID: 9872937

Bimal, S., S.K. Singh, S. Sinha, K. Pandey and P.K. Sinha et al., 2008. Leishmania donovani: Role of $\mathrm{CD} 2$ on CD4+T-cell function in Visceral Leishmaniasis. Exp. Parasitol., 118: 238-246. DOI: 10.1016/j.exppara.2007.08.009

Carrera, L., R.T. Gazzinelii, R. Badolato, S. HIney and W. Muller et al., 1996. Leishmania promastigotes selectively inhibit interleukin 12 induction in bone marrow-derived macrophages from susceptible and resistant mice. J. Exp Med., 183: 515-26. DOI: 10.1084/jem.183.2.515

Carvalho, E.M., O. Bacellar, C. Brownell, T. Regis and R.L. Coffman, 1994. Restoration of IFN-gamma production and lymphocyte proliferation in visceral leishmaniasis. J. Immunol., 152: 5949-5956. PMID: 8207220

Chulay, J.D. and A.D. Bryceson, 1983. Quantitation of amastigotes of Leishmania donovani in smears of splenic aspirates from patients with visceral leishmaniasis. Am. J. Trop. Med. Hyg., 32: 475-479. PMID: 6859397
Cutolo, M., S. Capellino, P. Montagna, P. Ghiorzo and A. Sulli et al., 2005. Sex hormone modulation of cell growth and apoptosis of the human monocytic/macrophage cell line. Arthritis Res. Ther., 7: R1124-R32. DOI: 10.1186/ar1791

D’Agostino, P., S. Milano, C. Barbera, G. Di Bella and M. La Rosa et al., 1999. Sex hormones modulate inflammatory mediators produced bymacrophages. Ann. NY Acad Sci., 876: 426-429. DOI: 10.1111/j.1749-6632.1999.tb07667.x

Danel, L., G. Souweine, J.C. Monier and S. Saez, 1983. Specific estrogen binding sites in human lymphoid cells and thymic cells. J Steroid Biochem., 18: 559563. DOI: 10.1016/0022-4731(83)90131-0

Das, V.N., A. Ranjan, S. Bimal, N.A. Siddiquea and K. Pandey et al., 2005. Magnitude of unresponsiveness to Sodium Stibogluconate in the treatment of Visceral Leishmaniasis in Bihar. Natl. Med. J. Ind., 18: 131-133. PMID: 16130613

Desjeux, P., 1992. Human leishmaniases: Epidemiology and public health aspects. World Health Stat. Q., 45: 267-75. PMID: 1462660

Desjeux, P., 1996. Leishmaniasis: Public health aspects and control. Clin Dermatol., 14: 417-423. DOI: 10.1016/0738-081X(96)00057-0

Desjeux, P., 2004. Leishmaniasis: Current situation and new perspectives. Comp. Immunol Microbiol. Infect. Dis., 27: 3 05-18. PMID: 15225981

Ghalib, H.W., M.R. Piuvezam, Y.A. Skeiky, M. Siddig and F.A. Hashim et al., 1993. Interleukin-10 production correlates with pathology in human Leishmania donovani infections. J. Clin. Invest., 92: 324-329. DOI: 10.1172/JCI116570

Ghosh, J., C.S. Lal, K. Pandey, V.N. Das and P. Das et al., 2011. Human visceral leishmaniasis: Decrease in serum cholesterol as a function of splenic parasite load. Ann. Trop. Med. Parasitol., 105: 267-271. DOI: $10.1179 / 136485911 X 12899838683566$

Gomes-Pereira, S., O.R. Rodrigues, N. Rolao, P.D. Almeida and G.M. Santos-Gomes, 2004. Hepatic cellular immune responses in mice with "cure" and "non-cure" phenotype to Leishmania infantum infection: Importance of CD8 $+\mathrm{T}$ cells and TGF- $\beta$ production. FEMS Immun Med. Microbiol., 41: 5968. DOI: 10.1016/j.femsim.2004.01.003

Greenblatt, C.L., 1980. The present and future of vaccination for cutaneous leishmaniasis. Prog. Clin. Biol. Res., 47: 259-85. PMID: 7010374 
Greenblatt, H.C. and D.L. Rosenstreich, 1984. Trypanosoma rhodesiense infection in mice: Sex dependence of resistance. Infect. Immun., 43: 337-40. PMID: 6690408

Grigoriadis, G., Y. Zhan, R.J. Grumont, D. Metcalf and E. Handman et al., 1996. The Rel subunit of NFkappa B-like transcription factors is a positive and negative regulator of macrophage gene expressiondistinct roles for Rel in different macrophage populations. EMBO J., 15: 7099-7107.

Jeronimo, S.M., P. Duggal, R.F. Braz, C. Cheng and G.R. Monteiro et al., 2004. An emerging periurban pattern of infection with Leishmania chagasi, the protozoan causing visceral leishmaniasis in northeast Brazil. Scand J. Infect Dis., 36: 443-449. DOI: 10.1080/00365540410020451

Jones, D.E., L.U. Buxbaum and P. Scott, 2000. IL-4independent inhibition of IL-12 responsiveness during Leishmania amazonensis infection. J. Immunol., 165: 364-372. PMID: 10861073

Jones, L.A., J.P. Anthony, F.L. Henrique, R.E. Lyons and M.B. Nickdel et al., 2008. Toll-like receptor4-mediated macrophage activation is differentially regulated by progesterone via the glucocorticoid and progesterone receptors. Immunology, 125: 59-69. DOI: 10.1111/j.13652567.2008.02820.x

Karp, C.L., S.H. El-Safi, T.A. Wynn, M.M. Satti and A.M. Kordofani et al., 1993. In vivo cytokine profiles in patient with kala-azar marked elevation of both interleukin-10 and interferon gamma. J. Clin Invest, 91: 1644-1648. DOI: 10.1172/JCI116372

Kenney, R.T., D.L. Sacks, A.A. Gam, H.W. Murray and S. Sunder, 1998. Splenic cytokine responses in Indian Kala-azar before and after treatments. J. Infect. Dis., 177: 815-818. DOI: 10.1086/517817

Kiyota, M., M. Korenaga, Y. Nawa and M. Kotani, 1984. Effect of androgen on the expression of the sex differences in susceptibility to infection with Strongyloides ratti in C57BL/6 mice. Aust. J. Exp. Biol. Med. Sci., 62: 607-618. DOI: 10.1038/icb.1984.58

Lal, C.S., A. Kumar, S. Kumar, K. Pandey and N. Kumar et al., 2007. Hypocholesterolemia and increased triglyceride in paediatric visceral leishmaniasis. Clin. Chim. Acta, 382: 151-153. DOI: 10.1016/j.cca.2007.04.007
Lal, C.S., N. Verma, V.N. Rabidas, A. Ranjan and K. Pandey et al., 2010. Total serum cholesterol determination can provide understanding of parasite burden in patients with visceral leishmaniasis infection. Clin. Chim. Acta, 411: 2112-2113. DOI: 10.1016/j.cca.2010.08.041

Lezama-Davila, C.M., S. Oghumu, A.R. Satoskar and A.P. Isaac-Marquez, 2007. Sex-associated susceptibility in humans with chiclero's ulcer: Resistance in females is associated with increased serum-levels of GMCSF. Scand J. Immunol., 65: 210-211. DOI: 10.1111/j.1365-3083.2006.01887.x

Li, Q. and I.M. Verma, 2002. NF-kappa B regulation in the immune system. Nat. Rev. Immunol., 2: 725734. DOI: $10.1038 /$ nri910

Miller, L. and J.S. Hunt, 1998. Regulation of TNF-alpha production in activated mouse macrophages by progesterone. J. Immunol., 160: 5098-5104. PMID: 9590261

Munoz, G. and C.R. Davies, 2006. Leishmania panamensis transmission in the domestic environment: the results of a prospective epidemiological survey in Santander. Columbia. Biomedica, 26: 131-44. PMID: 17361849

Murray, H.W. and S. Delph-Etienne, 2000. Role of indogenous gamma interferon and macrophage microbicidal mechanisms in experimental visceral leishmaniasis. Infect. Immun., 68: 288-293. DOI: 10.1128/IAI.68.1.288-293.2000

Piccinni, M.P., M.G. Giudizi, R. Biagiotti, L. Beloni and L. Giannarini et al., 1995. Progesterone favors the development of human $\mathrm{T}$ helper cells producing Th2-type cytokines and promotes both IL-4 production and membrane CD30 expression in established Th1 cell clones. J. Immunol., 155: 128133. PM ID: 7541410

Reithinger, R., M. Mohsen, K. Aadil, M. Sidiqi and P. Erasmus et al., 2003. Anthroponotic cutaneous leishmaniasis, Kabul, Afghanistan. Emerg Infect. Dis., 9: 727-729. DOI: 10.3201/eid0906.030026

Salotra, P., G. Sreenivas, G.P. Pogue, N. Lee and H.L. Nakhasi et al., 2001. Development of a speciesspecific PCR assay for detection of leishmania donovani in clinical samples from patients with kala-azar and post-kala-azar dermal leishmaniasis. J. Clin. Microbiol., 39: 849-854. DOI: 10.1128/JCM.39.3.849-854.2001 
Sanjabi, S., A. Hoffmann, H.C. Liou, D. Baltimore and S.T. Smale, 2000. Selective requirement for c-Rel during IL-12 p4gene induction in macrophages. Proc. National Acad. Sci., USA, 97: 12705-12710. DOI: $10.1073 /$ pnas.230436397

Satoskar, A., H.H. Al-Quassi and J. Alexander, 1998. Sex-determined resistance against Leishmania mexicana is associated with the preferential induction of a Th1-like response and IFN-gamma production by female but not male DBA/2 mice. Immunol Cell Biol., 76: 159-166. DOI: 10.1046/j.1440-1711.1998.00730.x

Shiddo, S.A., A.A. Mohamed, H.O. Akuffo, K.A. Mohamud and A.A. Herzi et al., 1995. Visceral leishmaniasis in Somalia: Prevalence of markers of infection and disease manifestations in a village in an endemic area. Trans. R Soc. Trop. Med. Hyg., 89: 361-365. DOI: 10.1016/0035-9203(95)90008-X

Sica, A., G. Melillo and T. Musso, 1996. Regulation of inducible nitric oxide synthase expression in INgamma-treated murine macrophages cultured under hypoxic conditions. J. Immunol., 157: 2638-2644.

Simons, K. and D. Toomre, 2000. Lipid rafts and signal transduction. Nat. Rev. Med. Cell Biol., 1: 31-9. DOI: $0.1038 / 35036052$

Singh, D., K. Pandey, V.N. Das, S. Das and N. Verma et al., 2013. Evaluation of rK-39 Strip test using urine for diagnosis of visceral leishmaniasis in an endemic region of India. Am. J. Trop. Med. Hyg., 88: 222226. DOI: $10.4269 /$ ajtmh.2012.12-0489

Singh, D., K. Pandey, V.N. Das, S. Das and S. Kumar et al., 2009. Novel noninvasive method for diagnosis of visceral leishmaniasis by rK39 testing of sputum samples. J. Clin. Microbiol., 47: 2684-2685. DOI: 10.1128/JCM.00988-09

Snider, H., C. Lezama-Davila, J. Alexander and A.R. Satoskar, 2009. Sex hormones and modulation of immunity against leishmaniasis. Neuroimmunomodulation, 16: 106-113. DOI: 10.1159/000180265

Sundar, S., S.G. Reed, V.P. Singh, P.C. Kumar and H.W. Murray, 1998. Rapid accurate field diagnosis of Indian visceral leishmaniasis. Lancet, 351: 563-565. DOI: 10.1016/S0140-6736(97)04350-X
Sundar, S., T.K. Jha, C.P. Thakur, S.K. Bhattacharya and M. Rai, 2006. Oral miltefosine for the treatment of Indian visceral leishmaniasis. Tran. R Soc. Trop Med. Hyg., 1: S26-33. PMID: 16730038

Sundar, S., V.P. Singh, S. Sharma, M.K. Makharia and H.W. Murray, 1997. Response to interferon gamma plus pentavalent antimony in Indian visceral leishmaniasis. J. Infect. Dis., 176: 1117-1119. DOI: $10.1086 / 516526$

Taylor, A.P. and H.W. Murray, 1998. Therapeutic effect of interferon-gamma gene transfer in experimental visceral leishmaniasis. J. Infect. Dis., 178: 908-911. DOI: $10.1086 / 515354$

Thakur, C.P. and S. Narayan, 2004. A comparative evaluation of amphotericin B and sodium antimony gluconate, as first-line drugs in the treatment of Indian visceral leishmaniasis. Ann. Trop. Med. Parasitol., 98: 129-138. DOI: 10.1179/000349804225003154

Thakur, C.P., D.K. Mitra and S. Narayan, 2003. Skewing of cytokine profiles towards $\mathrm{T}$ helper cell type 2 response in visceral leishmaniasis patients unresponsive to sodium antimony gluconate. Trans. R Soc. Trop. Med. Hyg., 97: 409-412. PMID: 15259468

Wunderlich, F., W.P. Benten, M. Lieberherr, Z. Guo and O. Stamm et al., 2002. Testosterone signaling in T cells and macrophages. Steroids, 67: 535-538. DOI: 10.1016/S0039-128X(01)00175-1

Yin, G., Z. Guo, L. Yin, J. Zhao and Z. Qiao et al., 1998. Effect of testosterone on Leishmania donovani infection levels of murine bone marrow derivedmacrophages. Zhongguo Ji Sheng Chong Xue Yu Ji Sheng Chong Bing Za Zhi, 16: 251-255. PMID: 12078252

Zhang, H., J. Zhao, P. Wang and Z. Qiao, 2001. Effect of testosterone on Leishmania donovani infection of macrophages. Parasitol. Res., 87: 674-676. DOI: $10.1007 / \mathrm{s} 004360000354$ 